\title{
J95 - Epinato Based Planning Parameters for Medical Support to Operations other Than War (OOTW)
}

\section{Lt Col TO Jefferson}

OStJ,MSc,MRCGP,MFPHM,MIL,DRCOG,DTM\&H odc,RAMC

Army Medical Directorate, Keogh Barracks, Ash Vale, Hants GU12 SRR.

\section{Professor V Demicheli \\ MD,MSc \\ University of Pavia, Pavia, Italy}

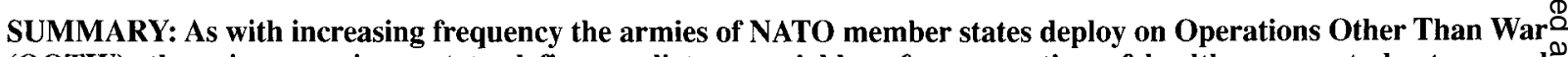
(OOTW), there is a requirement to define predictory variables of consumption of healthcare assets by type and geographical location of operations. This report presents the results of the analysis of the J95/EPINATO database of $\vec{\circ}$ operational and exercise deployments. Although the database is limited in size and scope results show a marked $\overrightarrow{-}$ difference in rates of incidence of EVENTS and in the proportion of first attendances to working days lost, both inc general and when analysed by deployment type. For instance Service Assisted or Protected Evacuations (SA/PE)? showed a relatively high incidence of first attendances and low incidence of working days lost for all reasons (or EVENTS) (214.5 per 1,000 personnel at risk per month - 95\% Confidence Interval - Cl: 198.8 to 230.3 and 23.9 working days lost per 1,000 personnel at risk per month $-95 \% \mathrm{Cl} 18.0$ to 29.8). The reverse is true for Counter Insurgency $\overrightarrow{\vec{A}}$ (COIN) type operations (111.55 per 1,000 personnel at risk per month - 95\% $\mathrm{Cl}$ : 110.9 to 112.2 and 161.25 working days $\vec{j}$ lost per 1,000 personnel at risk per month $95 \% \mathrm{Cl}$ : 160.5 to 162.0 ). Other findings include highest attendance rates in exercise deployments for all reasons (264.7 per 1,000 personnel per month $95 \% \mathrm{Cl}$ : 261.2 to 268.1$)$, highest hospitalisation rates in exercise and PSO deployments for all reasons (8.7 per 1,000 personnel per month 95\% Cl: 790 to 9.4 and 9.9 per 1,000 personnel per month $95 \% \mathrm{Cl}$ : 9.6 to 10.1) and the seasonal pattern, high incidence and lofv manpower impact (26.2 per 1,000 personnel per month $95 \% \mathrm{Cl}: 25.9$ to 26.5 and 3.5 per 1,000 personnel per monthe 95\% Cl: 3.4 to 3.6) of dermatological consultations on all operational deployments (the lowest of the spectrum being $\frac{\pi}{\sigma}$ COIN operations). No relationship was found between incidence of consultations, working days lost, hospitalisatiogss and distance of the deployment from the UK. Deployments to Africa show the highest incident of attendances and $\mathbb{E}^{\circ}$ working days lost for all reasons (530.7 per 1,000 personnel per month 95\% Cl: 524.2 to 537.3 and 106.5 per $1,000 \%$ personnel per month $95 \% \mathrm{Cl}$ : 102.5 to 110.6). The variability in epidemiological profiles in this analysis demonstrates $\square$ the dangers of exclusive reliance on synthetic classifications of reasons for attendances such as the traditional DNBII breakdown and on point estimates of incidence. As the database expands, further analysis will become possible.

\section{Introduction}

Since the end of the Cold War, the Armed Forces of the UK and of several member states of NATO have been involved in a growing number of OOTW around the globe. Although initially such operations were carried out outside NATO (within an informal coalition or the UN), more recently the military structure of NATO has been involved in air operations and, lately, in the provision of ground forces. This process culminated in the deployment to the territory of the Former Republic of Yugoslavia (FRY) of approximately 50,000 Implementation Force (IFOR) troops under NATO control at the end of 1995, and is still under way with the continuation of the operations in the FRY under the aegis of Stabilisation Force (SFOR). The deployment of a large multinational military contingent to difficult theatres such as the FRY, has focused the attention of commanders and planners on the health of their troops. The maintenance of health is of prime importance to military commanders for several reasons. Firstly, fitness prevents losses through sickness, thus maximising manpower resources at the disposal of commanders. Secondly, all military personnel are sent by their respective governments to deal with difficult problems in difficult situations. As such circumstances themselves may be a cause of morbidity or mortality, $\stackrel{\mathbb{Q}}{ }$ governments owe a duty of care to their personnel. This $\overrightarrow{\vec{B}}$ principle was enunciated as early as 1865 by Edmund Parkes 3 who wrote of the State's obligation to military personnel: "The State employs a large number of men, whom it places? under its own social and sanitary conditions. It removes from 3 them much of the self-control with regard to hygienic rules which other men possess and it is therefore bound by every principle of honest and fair contract to see that these men are $\vec{\Phi}$ in no way injured by the system. But more than this: it is as much bound by its self interest. It has been proved over and?over again that nothing is so costly in all ways as disease. 3 . and that nothing is so remunerative as the outlay which. augments health, and in doing so, augments the amount and value of the work done" (1).

Such sentiments have a more modern echo in the aftermath to the Gulf War (2). Thirdly, a real or perceivedo lack of care can create suspicion of governments and armed forces alike, undermining the public's confidence in the o ability of the military community to carry out their tasks (2).N Historically, duty of care has been discharged by deployingN్ట్ medical assets to operational theatres on a scale based on a mixture of personal experience and use of planning

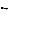


parameters. Within the UK and NATO, parameters used for the planning and resourcing of general war-fighting operations are based on the seminal ACE Directive number 85-8 (ACE Dir 85-8 for short) (3). ACE Dir 85-8 contains a brief but authoritative review of historical casualty rates from the French Revolution to the Yom-Kippur War, mainly based on the work of Dupuy (4) and Kuhn (5). Both studies refer to historical war scenarios and adopt the traditional approach of classifying casualty occurrences into Battle Injury (BI), Disease (D) and Non-battle Injury (NBI). The studies show how very high attrition rates generated in World War One have progressively reduced in more recent wars.

In order to structure medical support to the mission, and hence to the likely casualty load, there must be careful assessment of a wide variety of health threats and their effects on military personnel that can be transferred and compared across national boundaries. Historically-derived parameters from conflicts at the higher end of the intensity spectrum are unlikely to be appropriate for use in an operational scenario other than war. Indeed in the intention of its authors, ACE Dir 85-8 and its parameters were never meant to be extrapolated outside war scenarios. As future involvement in OOTW is highly likely for both UK and NATO forces, the lack of equivalent parameters for the spectrum of different OOTW impedes rationale planning. Past attempts at comparing planning assumptions based both on broad groupings, such as BI/DNBI, and on more detailed event descriptions have been bedevilled by a lack of comparability of casualty data (6). The IFOR/SFOR deployment has seen the introduction of J95, a military morbidity surveillance system based on the International Classification of Diseases (ICD). J95 can be used in both operational and non-operational settings (i.e. barracks) and allows for the variation of EVENT (main reason for attendance) categories, in a concertina-like fashion, as suggested either by a different morbidity pattern, or as $D$ dictated by changing operational requirements. EVENT categories expand or contract according to need, thus allowing flexibility of coverage while retaining $\underset{\otimes}{\circ}$ comparability thanks to the use of the internationally accepted ICD base (7). This has enabled the production of $\bigcirc$ both an operational variant and the basis of the current NATO health surveillance system called EPINATO. This is $\Rightarrow$ currently being used by SFOR in the FRY and is divided $\stackrel{\rho}{?}$ into 24 EVENT categories which can be subsequently grouped into the traditional BI/DNBI division. By October 1997, the average population coverage of the system was 31,962. The database containing data from the FRY operational version of J95 and EPINATO also contains J95based data from other OOTW and exercise deployments undertaken by the British Army. For the FRY the database contains data relating to MNDSW for the months of January to September 1996 and to MNDSE and Command Support for the months July to November 1996 and thereafter for the whole SFOR contingent (on average made up of 18 nations). J95, originally developed by the UK Ministry of Defence following the outcome of a pilot study (6), has $\overrightarrow{+}$ provided a data gathering tool which allows analysis of real $\mathcal{N}$ data from the group of OOTW currently in the database. We report on the results of a study aimed at describing morbidity patterns in data from OOTW and exercis deployments currently in the J95/EPINATO database and defining variables likely to be predictory of healthcar resource consumption.

\section{Methods}

Data from the J95/EPINATO database relating to OOT were described on the basis of deployment type. For typology and definition of deployments see Annex A. Da relating to exercise deployments carried out by the British

Table 1

Deployments by type, date, timespan of available data, total population at risk and continent.

\begin{tabular}{|c|c|c|c|c|c|}
\hline Name & Type & Year & Duration & Population at Risk & Continent \\
\hline Dragons Breath & Exercise & 1996 & 1 Month & 740 & Europe \\
\hline Grand Prix 1 & Exercise & 1996 & 1.5 Months & 900 & Africa \\
\hline Grand Prix 2 & Exercise & 1996 & 1.5 Months & 1150 & Africa \\
\hline Grand Prix 3 & Exercise & 1997 & 2 Months & 1720 & Africa \\
\hline Hard Fall & Exercise & 1996 & 3 Months & 2500 & Europe \\
\hline High Slope & Exercise & 1997 & 1 Month & 26 & Africa \\
\hline Lion Sun & Exercise & 1997 & 1 Month & 89 & Europe \\
\hline Trumpet Dance 1 & Exercise & 1997 & 2 Months & 1500 & The Americas \\
\hline Trumpet Dance 2 & Exercise & 1997 & 2 Months & 1370 & The Americas \\
\hline Purple Star & Exercise & 1996 & 1 Month & 9579 & The Americas \\
\hline Ulan Eagle & Exercise & 1996 & 1 Month & 3500 & Europe \\
\hline Determinant & $\begin{array}{c}\text { Services } \\
\text { Aassisted/Protected } \\
\text { Evacuation }\end{array}$ & 1997 & 2 Months & 960 & Africa \\
\hline Chantress & $\begin{array}{c}\text { Peace Support Operations } \\
\text { - Peacekeeping }\end{array}$ & 1995 & 2 Months & 1200 & Africa \\
\hline $\begin{array}{l}\text { Former Republic } \\
\text { of Yugoslavia }\end{array}$ & $\begin{array}{l}\text { Peace Support Operations } \\
\text {-Wider Peacekeeping }\end{array}$ & $1996-97$ & $1 \overline{3 \text { Months }}$ & $\overline{172973}$ & Europe \\
\hline Gabriel & Humanitarian & 1994 & 2.5 Months & $\overline{2300}$ & Africa \\
\hline Northern Ireland & Coin/Internal Security & $1996-97$ & 18 Months & 332840 & Europe \\
\hline
\end{tabular}


Table 2

Slected ten J95/EPINATO EVENTS analysed.

\begin{tabular}{|c|c|}
\hline EVENTS & J95 EVENT CODES \\
\hline All Events & 1 to 22 \\
\hline Intestinal Infections & 1 \\
\hline Infections & $1+2+3$ \\
\hline Respiratory Diseases & 8 \\
\hline Digestive Diseases & $10+11$ \\
\hline Dermatological & 13 \\
\hline Musculo-Skeletal & $17+15+16$ \\
\hline RTA Injuries & 18 \\
\hline Injuries other than War and RTA & 22 \\
\hline Other Diseases & \\
\hline
\end{tabular}

Army during 1996-97 were included in the study. A list of deployments by type, date, timespan of available data, monthly population at risk and continent is at Table 1. First attendances at primary care outlets, working days lost and admissions to hospital relating to ten J95/EPINATO selected EVENTS were analysed. The ten events are listed in Table 2. Data were analysed by deployment type and continent and expressed in rates per 1,000 personnel at risk per month (within 95\% confidence intervals). For those deployments (FRY and COIN) which had the longest timespan databases, monthly trends were also calculated. For first consultations, the proportion of first to subsequent attendances was also calculated. Detailed tabulations of all ten analyses are available from the authors on request. For the sake of brevity, graphical results of only five of the ten EVENTS are contained in this report (All EVENTS, Respiratory events, Dermatological EVENTS, Musculo-skeletal EVENTS including knee and back problems, Injuries other than those caused by War and Road Traffic Accidents RTA).

\section{Results}

Figure 1 shows rates of first attendances and working days lost per 1,000 personnel at risk for All EVENTS by deployment type, continent and month (for the FRY and COIN/Northern Ireland deployments). Figure 2 shows rates of first attendances and working days lost per 1,000 personnel at risk for Respiratory EVENTS by deployment type, continent and month (for the PSO/FRY and COIN/Northern Ireland deployments). Figure 3 shows rates of first attendances and working days lost per 1,000 personnel at risk for Dermatological EVENTS by deployment type, continent and month (for the PSO/FRY and COIN/Northern Ireland deployments). Figure 4 shows rates of first attendances and working days lost per 1,000 personnel at risk for Musculo-Skeletal EVENTS by deployment type, continent and month (for the PSO/FRY and COIN/Northern Ireland deployments). Figure 5 shows rates of first attendances and working days lost per 1,000 personnel at risk for Injuries other than those caused by War and RTAs by deployment type, continent and month (for the PSO/FRY and COIN/Northern Ireland deployments). Figure 6 shows rates of hospital admissions per 1,000 personnel at risk for all EVENTS, respiratory EVENTS,
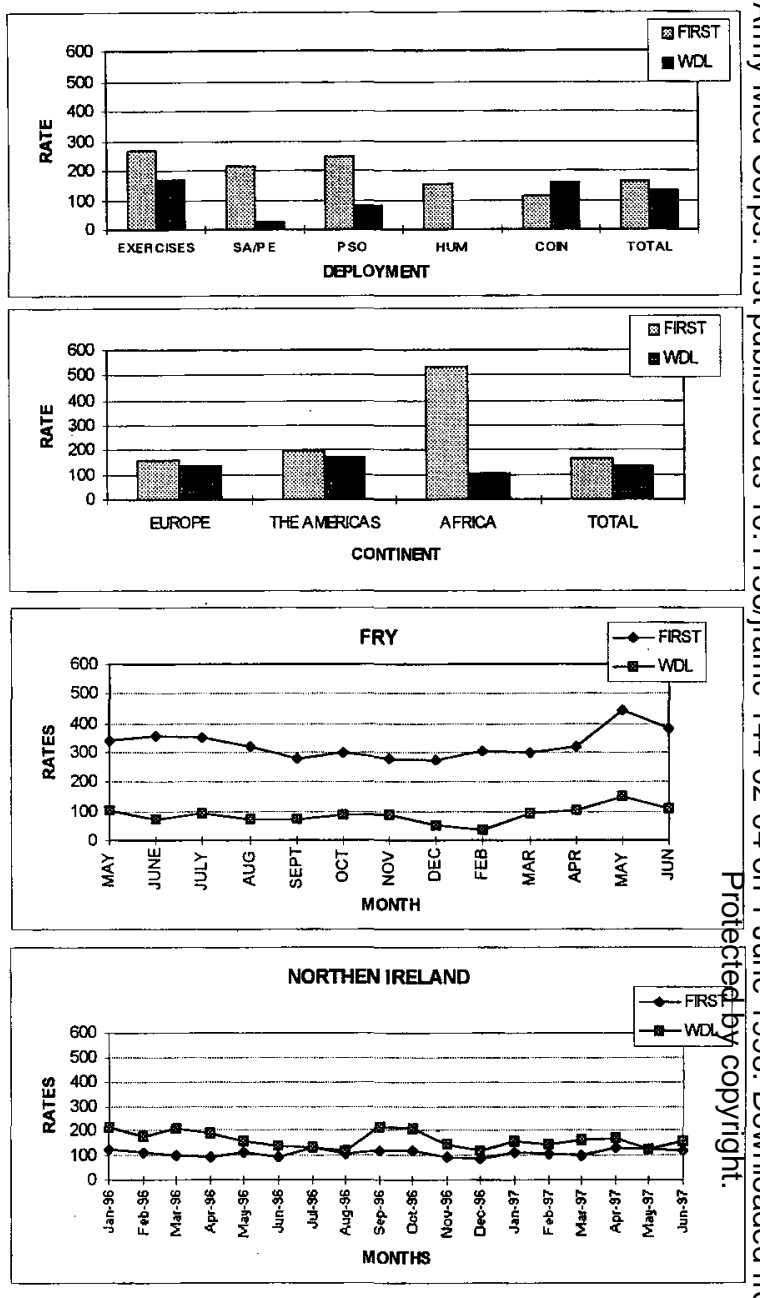

Fig 1. Rates of First Attendances and Working Days Lost for ALL EVENTS by deployment type, continent and month (FRY and NI only). (FIRST=First

Attendances; WDL=Working Days Lost)

(SA/PE=Service Assisted/Protected Evacuation; PSO=Peace Support Operations;

HUM=Humanitarian; COIN=Counter Insurgency/Internal Security)

musculo-skeletal EVENTS and Injuries other than those caused by War and RTAs by deployment type. Admissions for dermatological EVENTS were excluded because of their very low incidence.

\section{Discussion}

The data analysed so far show a marked difference in rates of incidence of EVENTS and in the proportion of first $\mathrm{N}$. attendances to working days lost, both in general and when $N$ analysed by deployment type. This is evident in Figures $1 \mathrm{~N}$ relating to all EVENTS (214.5 per 1,000 personnel at risk ${ }^{\omega}$ per month - 95\% CI: 198.8 to 230.3 and 23.9 working days 

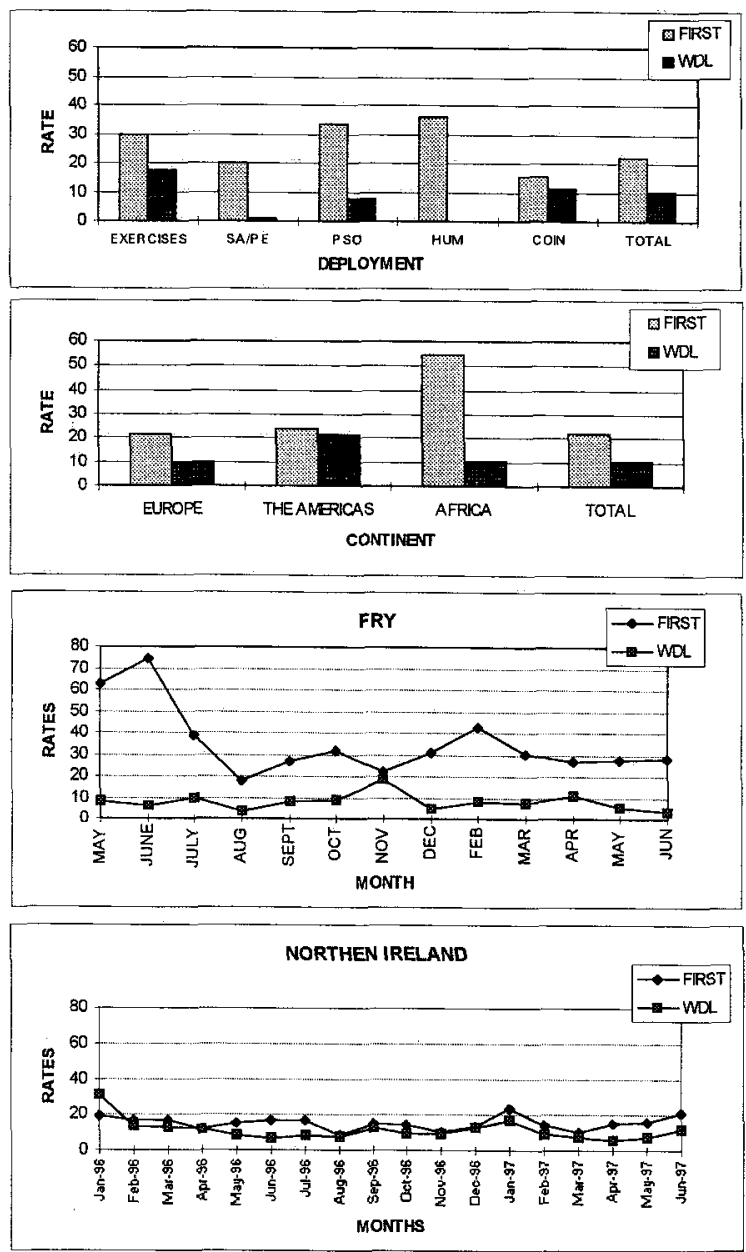

Fig 2. Rates of First Attendances and Working Days Lost for RESPIRATORY EVENTS by deployment

type, continent and month (FRY and NI only).

(FIRST=First Attendance; WDL=Working Days

Lost) $(\mathrm{SA} / \mathrm{PE}=$ Service Assisted/Protected Evacuation; PSO=Peace Support Operations;

HUM=Humanitarian; COIN=Counter Insurgency/Internal Security)

lost per 1,000 personnel at risk per month - 95\% CI 18.0 to 29.8) and 4 (relating to Musculo-Skeletal EVENTS) where SA/PE and PSO - type deployments have relatively high incidences of first attendances for events which appear to have a low impact on manpower. The reverse is true for COIN-type operations (111.55 per 1,000 personnel at risk per month - 95\% CI: 110.9 to 112.2 and 161.25 working days lost per 1,000 personnel at risk per month $95 \% \mathrm{CI}$ : 160.5 to 162.0 ). One possible explanation for such a finding could be to the semi-permanent character of the Northern Ireland COIN campaign in which unit healthcare workers may be more likely to award long periods of time off to recover from the effects of disease. The COIN data in this
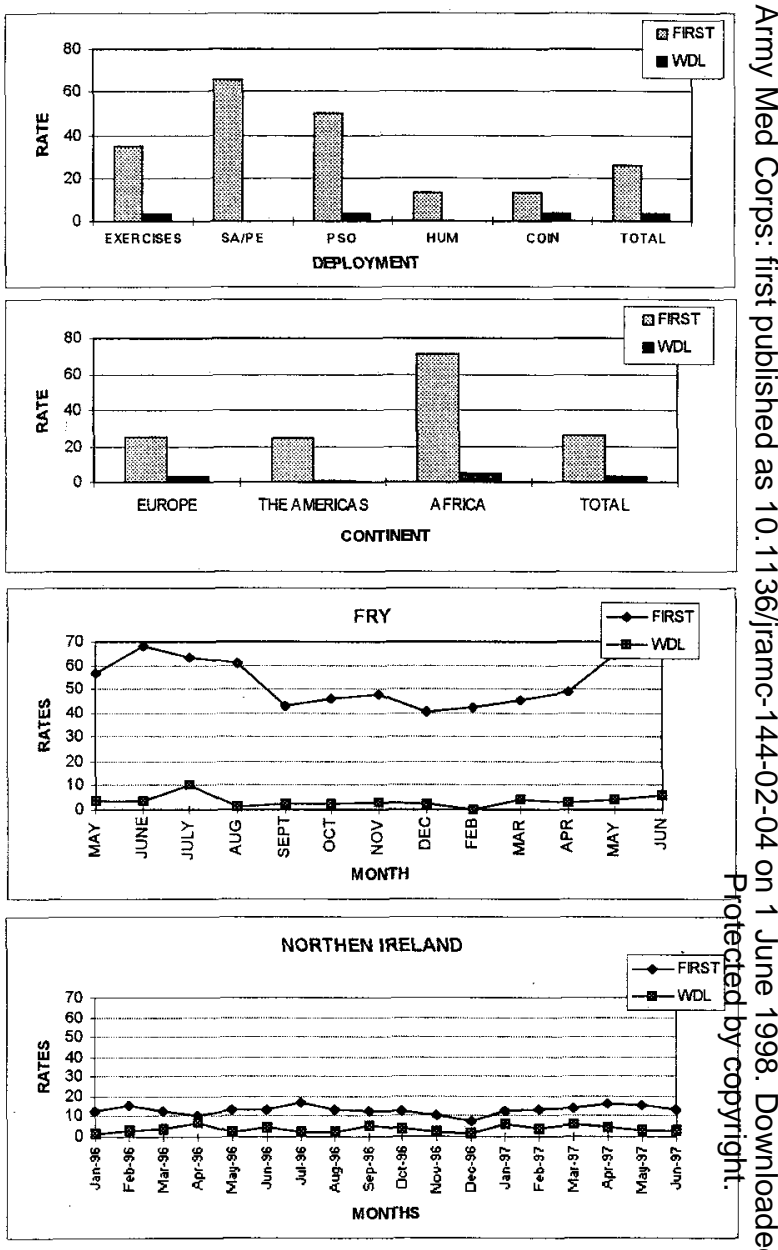

Fig 3. Rates of First Attendances and Working Days Lost for DERMATOLOGICAL EVENTS by deployment type, continent and month (FRY and NI only). (FIRST $=$ First Attendances; WDL $=$ Working

Days Lost) (SA/PE=Service Assisted/Protected

Evacuation; PSO=Peace Support Operations; HUM=Humanitarian; COIN=Counter Insurgency/Internal Security)

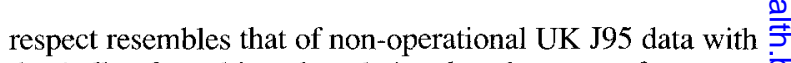
the bulk of working days being lost because of overuse musculo-skeletal conditions (including knees and back problems). This "stability" effect is most striking when $\frac{\delta}{3}$ monthly trends for Northern Ireland/COIN and FRY/PSO

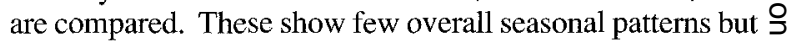
a marked difference in the incidence between first $\rightarrow$ attendances and working days lost. Additionally there may be a suggestion of a reduction and stabilisation of the $N$ incidence of injuries in the FRY, although this observation may have been affected by the presence of two different $\mathrm{N}$ denominators in the FRY dataset. Further analysis of future $\omega$ data is required before confirmation of this trend can be 

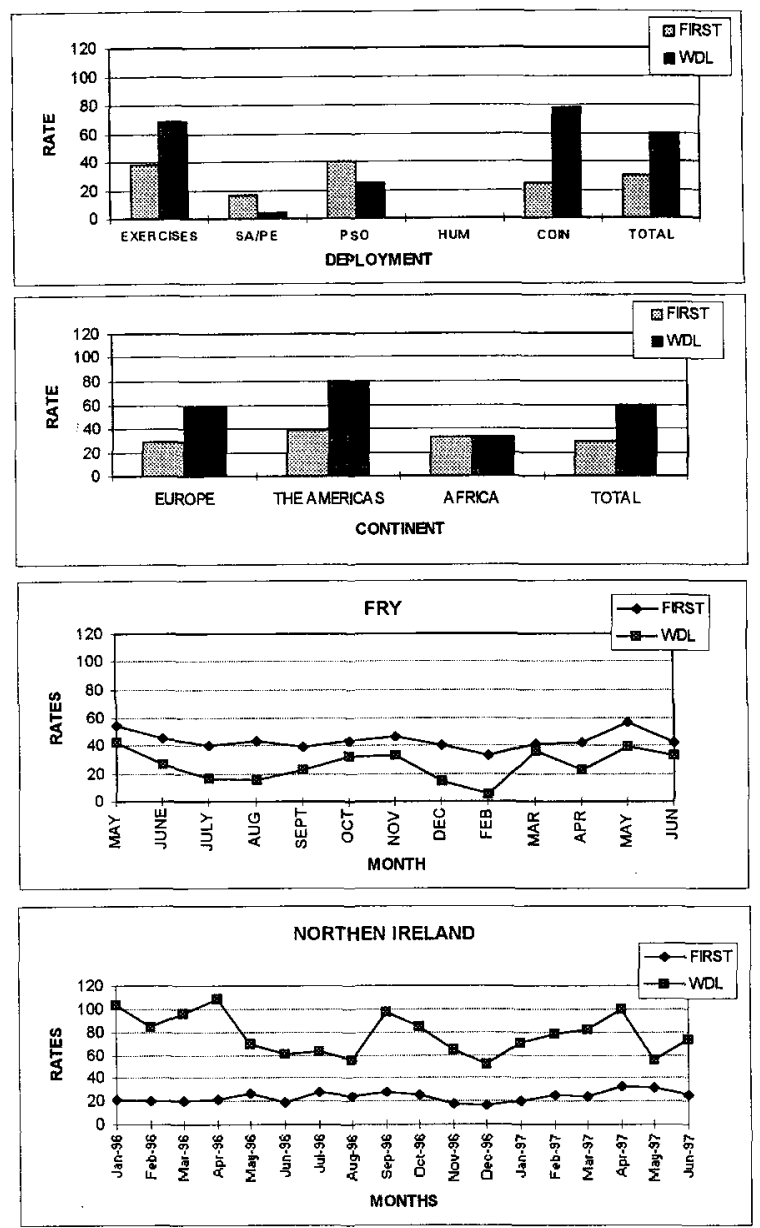

Fig 4. Rates of First Attendances and Working Days

Lost for MUSCULO-SKELETAL EVENTS by deployment type, continent and month (FRY and NI only). (FIRST=First Attendances; WDL=Working Days Lost)

(SA/PE=Service Assisted/Protected Evacuation; PSO=Peace Support Operations;

HUM=Humanitarian; COIN=Counter Insurgency/Internal Security)

given. Exercise deployments show the highest incidence of consultations and overall a relatively high rate of working days lost (264.7 per 1,000 personnel per month 95\% CI: 261.2 to 268.1 ), possibly due to their dynamic nature with ample opportunities for injuries and musculo-skeletal problems due to overuse and fatigue. Another aspect of this "stability effect" may be seen in trends of consultations for dermatological EVENTS. These have a very high incidence and low impact in working days lost (26.2 per 1,000 personnel per month $95 \%$ CI: 25.9 to 26.5 and 3.5 per 1,000 personnel per month $95 \% \mathrm{CI}: 3.4$ to 3.6 ) and a seasonal pattern on operational deployments (such as in the FRY) with the lowest being in COIN-type deployments, probably
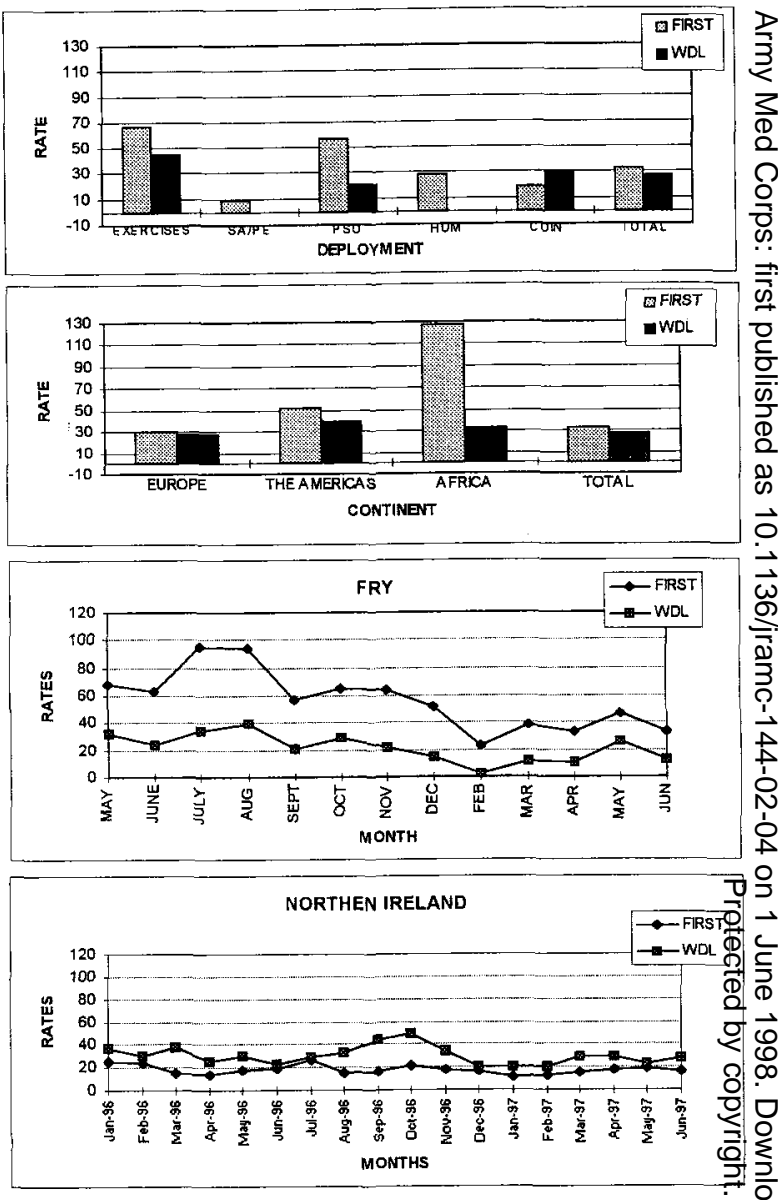

Fig 5. Rates of First Attendances and Working Days Lost for INJURIES O'THER THAN WAR AND RTA by deployment type, continent and month (FRY and NI only). (FIRST $=$ First Attendances; WDL $=$ Working

Days Lost) (SA/PE=Service Assisted/Protected

Evacuation; PSO=Peace Support Operations;

HUM=Humanitarian; COIN=Counter Insurgency/Internal Security)

a reflection of hygienic and environmental conditions. PSOs and exercise deployments have the highest rates of hospital admissions for all EVENTS (8.7 per 1,000 personnel per month $95 \%$ CI: 7.9 to 9.4 and 9.9 per $1,000 \frac{\text { O }}{3}$ personnel per month $95 \%$ CI: 9.6 to 10.1 for exercisedeployments). There may be two explanations for this $\frac{\mathrm{O}}{3}$ observation. Firstly exercise deployments are brief and

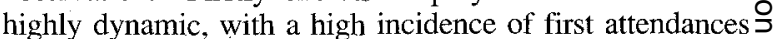
and low convalescing potential which is inevitably reflected in the number of hospital admissions. Conversely, the explanation for the finding of high hospitalisation in both N PSOs may be given by the well known offer-led increase in hospitalisation. Both PSO-type operations in the database 0 had high hospital bed provision. A definitive answer will only be given by analysis of several PSO-type operation? 

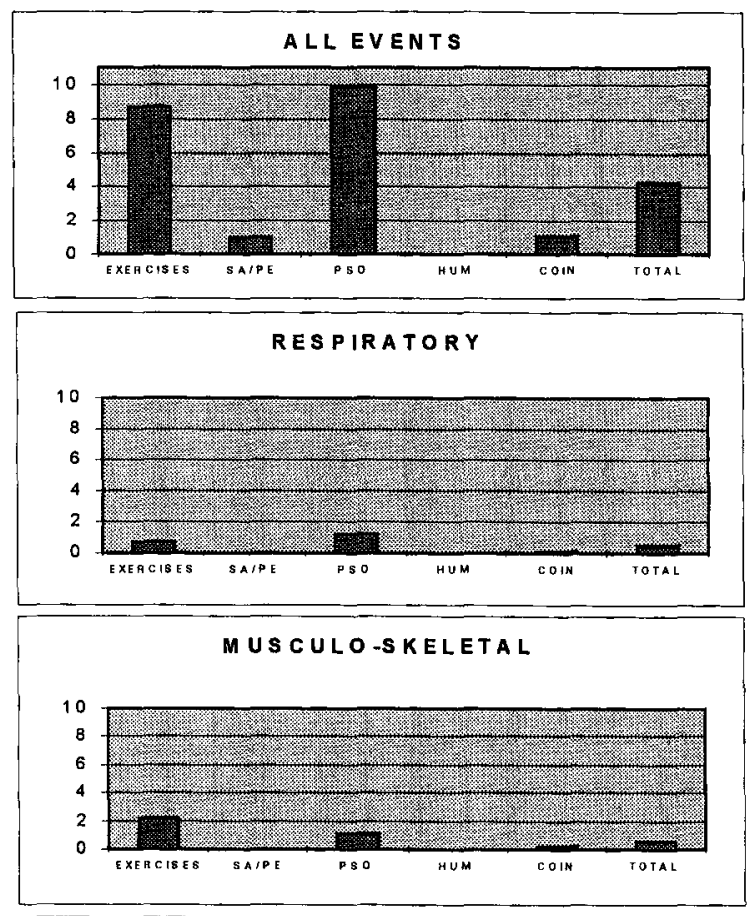

INJURIES other than Warand RTA

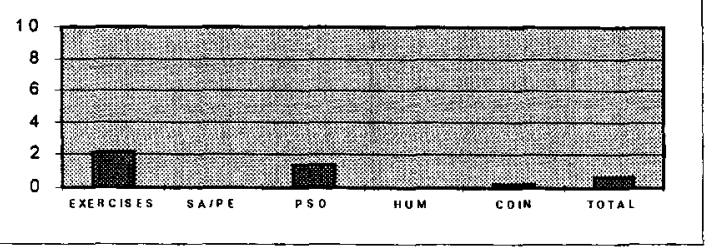

Fig 6. Rates of Hospital Admissions for ALL EVENTS, RESPIRATORY EVENTS, MUSCULOSKELETAL EVENTS AND INJURIES OTHER

THAN WAR AND RTA by deployment type.

(SA/PE=Service Assisted/Protected Evacuation; PSO=Peace Support Operation; HUM=Humanitarian; COIN=Counter Insurgency/Internal Security)

data stratified by availability of hospital beds. Analysis of distance from the UK and incidence of EVENTS, working days lost and hospitalisations by deployment type failed to reveal any correlation, although the small number of "distant" deployments in the database does not allow any conclusions to be drawn. Not surprisingly, however, deployments to Africa show the highest incidents of all EVENTS and working days lost. The database is limited in size and scope, with two deployments (COIN/Northern Ireland and PSO/FRY) contributing $80 \%$ of the EVENT data. As more nations adopt EPINATO as a morbidity surveillance tool and the database increases in size, more detailed analyses will become feasible. There remains a requirement to identify the most resource-intensive determinants of general morbidity and to distinguish between individual and environmental factors. The results of these analyses will provide a planning tool for resource $\Sigma$ allocation decisions for all contributing nations. $\stackrel{\perp}{\Omega}$ Additionally the continuation of EPINATO and the $\Omega$ introduction into the British Army of J97, a more detailed

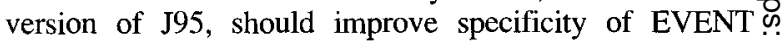
definition. The notable variability evident in the results of $\vec{\Rightarrow}$ this report is due to a variety of factors, only few of which $\stackrel{9}{9}$ have been analysed. However, such variability shows the difficulty and danger of relying exclusively on single estimate measures of morbidity such as the DNBI $\vec{\Phi}$

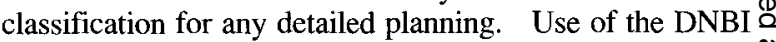
classification may have a role in top level briefing, so long as its users bear in mind its limitations. A demonstration of $\overrightarrow{0}$ this point is that three of the four detailed EVENT categories used in this analysis would have been subsumed in the $\vec{\omega}$ "disease" category. Equally potentially misleading is a universal incidence figure for all DNBI events.

\section{Acknowledgement}

The authors would like to thank Colonel AHM MacMillan L/RAMC and Miss C Morris for the help N received.

\section{ANNEX \\ Operations Other Than War (OOTW)}

\section{Deployment Type Definitions}

Peace Support Operations (PSO) - Operations other th War covering peacekeeping, wider peacekeeping aht peace enforcement. The term given to military operatio conducted on behalf of the United Nations.

PSOs are divided into:

Peacekeeping - Operations carried out with the consent of the belligerent parties in support of efforts to achieve or maintain peace in order to promote security and sustain life in areas of potential or actual conflict.

Wider Peacekeeping - The wider aspects of peacekeeping operations carried out with the consent of the belligerent parties but in an environment that may be highly volatile. Peace Enforcement - Operations carried out to restore peace between belligerent parties who do not all consent to the intervention and who may be engaged in combat? activities.

Counter Insurgency Operations (COIN) - Militaryo̊ operations carried out to complement those political, economic, psychological and civic actions necessary to응 defeat an armed insurgency and thereby sustain an existing $>$ state authority.

Services Assisted/Protected Evacuations - Operations $\widetilde{N}$ which have limited objectives such as the rescue of hostages, security of non-combatants or re-establishment of law and order. 


\section{REFERENCES}

1. PARKES EA. Manual of practical hygiene (edited by FSBF De Chaumont). London: J \& A Churchill 1878 : (fifth edition) 23-24.

2. LANCET. Bridging the Gulf (Editorial) Lancet 1996; 347: 341 .

3. Supreme Allied Headquarters Allied Powers Europe. ACE Medical support. Principles, policies and planning parameters (ACE Directive number 85-8). Brussels, 26 October 1993.

4. DUPUY TN. Attrition: forecasting battle casualties and equipment losses in modern war. Fairfax Virginia: Hero Books : 1990.
5. KUHN GWS. Ground forces casualty rate patterns, the empirical evidence. Logistics Management Institute Bethesda Maryland, September 1989.

6. GoOdman RC, RichardSON HD. Casualty estimation in open and guerrilla warfare. Ministry of Defence, $\bigcirc$ London 1995.

7. Jefferson TO, Demicheli V, Macmillan AHM. Pilot study of the introduction of the J95 health data collection system. JR Army Med Corps 1996; 142: 25 29. 